\title{
Gümüş nano materyallerin sentezi, karakterizasyonu ve antimikrobiyal aktiviteleri
}

\section{Synthesis, characterization and antimicrobial activities of silver nanomaterials}

\author{
Necmettin AKTEPE \\ Mardin ArtukluÜniversitesi, Hemşirelik Bölümü necmettinaktepe@ hotmail.com
}

\begin{tabular}{|c|c|}
\hline MAKALE BİLGILLERİ & ÖZET \\
\hline Makale geçmişi: & \multirow{5}{*}{$\begin{array}{l}\text { Gümüş nano materyallerin kullanım alanları oldukça yaygındır. Farklı sentezleme yöntemleri } \\
\text { ile elde edilebilirler. Bu çalışmada, gümüş nano materyaller (AgNP'ler) biyosentez yöntemi } \\
\text { kullanılarak ekonomik ve basit bir şekilde elde edildi. Sentez sonucunda elde edilen AgNP'ler } \\
\text { UV-visiblespektrofotometre (UV-Vis.), Taramalı Elektron Mikroskobu (SEM), X- Işınımı } \\
\text { Kırınımı Difraktrometresi (XRD), Fourier dönüşümü kızılötesi spektroskopisi (FTIR), Zeta } \\
\text { potansiyeli cihazları kullanılarak karakterize edildi. AgNP'lerin } 426.66 \mathrm{~nm} \text { dalga boyunda } \\
\text { maksimum absorbansa sahip oldukları, küresel morfolojik yapı sergiledikleri, } 17.68 \text { nm kristal } \\
\text { nano boyut ve yüzey yüklerinin -20.9 mV zeta potansiyeli dağılımı gösterdiği değerlendirildi. } \\
\text { Patojen mikroorganizmalar üzerinde Minumum İnhibisyon Konsantrasyonları (MİK) 0.03-0.5 } \\
\text { mg/L olarak mikrodilusyon yöntemi kullanılarak tespit edildi. }\end{array}$} \\
\hline Geliş: 2 Mart 2021 & \\
\hline $\begin{array}{l}\text { Düzeltme: } 12 \text { Mart } 2021 \\
\text { Kabul: } 12 \text { Mart } 2021\end{array}$ & \\
\hline Anahtar kelimeler: & \\
\hline $\begin{array}{l}\text { Zeta potansiyel, AgNP'ler, } \\
\text { biyosentez, SEM, MiK }\end{array}$ & \\
\hline
\end{tabular}

Doi: $10.24012 /$ dumf. 889403

\begin{tabular}{l}
\hline ARTICLE INFO \\
\hline Article history: \\
Received: 2 March 2021 \\
Revised: 12 March 2021 \\
Accepted: 12 March 2021 \\
\hline Keywords: \\
Bridge pier, local scour, clear \\
water scour, steady flow
\end{tabular}

* Sorumlu yazar / Correspondence

Necmettin AKTEPE

$\square$ necmettinaktepe@hotmail.com

\begin{abstract}
The usage areas of silver nanomaterials are quite common. They can be obtained by different synthesis methods. In this study, silver nanomaterials (AgNPs) were obtained economically and simply using the biosynthesis method. AgNPs obtained as a result of the synthesis were characterized by using UV-visiblespectrophotometer (UV-Vis.), Scanning Electron Microscope (SEM), X-Ray Diffraction Diffractometer (XRD), Fourier transform infrared spectroscopy (FTIR), Zeta potential devices. It was evaluated that AgNPs had maximum absorbance at $426.66 \mathrm{~nm}$ wavelength, exhibited spherical morphological structure, $17.68 \mathrm{~nm}$ crystal nano size and surface charges showed $-20.9 \mathrm{mV}$ zeta potential distribution. Minimum Inhibition Concentrations (MIC) 0.03-0.5 mg / $\mathrm{L}$ were determined on pathogenic microorganisms using microdilution method.
\end{abstract}




\section{Giriş}

Nanobiyoteknoloji çevre dostu anlayışa sahip tıp, biomedikal, fizik, biyoloji, kimya, malzeme mühendisliği gibi disiplinler arası çalışmalara olanak tanıyan hızlı gelişen önemli bir alandır. Farklı morfolojilere, kompozisyonlara ve yapilara sahip metal nano materyallerin elde edilmesi bottom-up (aşağıdan yukarı) ya da top down (yukarıdan aşağı) yaklaşımların kullanımları ile gerçekleştirilir [1], [2], [3]. Nanopartiküllerin geniş yüzey alanına sahip olmaları, yüksek 1sıl işlemlere dayanıklı olmaları kullanımlarına olan talebi artırmaktadır [4]. Metalik nano materyaller arasında gümüş $(\mathrm{Ag})$ [5], altın $(\mathrm{Au})$ [6], bakır $(\mathrm{Cu})$ [7], çinko $(\mathrm{Zn})$ [8] bunlardan bazılarıdır. Nano metaryaller fiziksel, kimyasal ve biyolojik yöntemler kullanılarak sentezlenebilirler. Biyosentezle nano materyallerin elde edilmesi uygulama sürecinde toksik kimyasalların olmayışı, yüksek enerji ihtiyacının olmayışı ile maliyetin düşük olması, basit bir işlem olması, medikal uygulamalar için biyouyumlu yap1 sergilemeleri biyosentez yöntemlerini diğer yöntemler karşısında daha çekici hale getirmektedir [4], [9].

AgNP'lerin biyosentezle elde edilmesinde bitkiler [10], mantarlar [11], algler [12], bakteriler [13] gibi biyolojik kaynaklar kullanılabilir. Bitkilerin yaprakları [14], meyveleri [15], kökleri [16], çiçekleri [17] veya bitkinin tamamı [18] kullanılarak elde edilen AgNP'lerin daha fazla miktarlarda elde edilmesi, kararlı olmalar1 [19], sentezin basit ve maliyetin düşük olması [15] bitki kaynakları kullanılarak yapılan sentez çalışmalarına olan ilgiyi artırmaktadır. Fitokimyasalların yapısını oluşturan alkolloidler, terpenoidler, flavonoidler, enzimler, aminoasitler, fenolikler vs. biyoaktif bileşenler sulu yapıda $\mathrm{Ag}^{+}$iyonlarını indirgeyerek $\mathrm{Ag}^{\mathrm{O}}$ oluşturarak AgNP'leri meydana getirirler [20], [21].

$\mathrm{Bu}$ araştırma çalışmasında, Mardin bölgesinde yetişen çörekotu (Nigella sativa L.) bitkisinin yeşil kısımları ile elde edilen özütle AgNP'lerin basit, kolay bir işlemle biyosentezini gerçekleştirmek, karakterizasyonunu yapmak ve antimikrobiyal aktivitesini incelemek amaçlandı.

\section{Bitki özütü ve çözelti hazırlama}

Toplanan çörek otu birkaç kez çeşme suyu ve distile su ile yıkamanın ardından kurutuldu. Kuruyan bitkiden 100 gr alınıp 500 mL distile su ile kaynatılıp süzme yapıldıktan sonra elde edilen özüt biyosentez için hazır hale getirildi.

Sigma aldrich markalı $\mathrm{AgNO}_{3}$ (gümüş nitrat) tuzundan 10 (milimolar) $\mathrm{mM}$ konsantrasyonunda çözelti hazırlandı.

Mikrodilusyon yöntemi için ticari olarak satın alınan vankomisin, flukonazol ve kolistin antibiyotikleri kullanıldı.

\section{Biyosentez ve Karekterizasyon}

Hazırlanan bitki özütü ve $10 \mathrm{mM} \mathrm{AgNO}_{3}$ çözeltisi 1:2 oranında karıştırılıp laboratuvar koşullarında basit bir elle çalaklamanın akabinde düz bir zemine biyosentez için bırakıldı.

UV-visible spektrofotometre (UV-Vis.) ve Fourier Dönüşümlü Kızılötesi spektroskopisi (FT-IR) Perkin E.O. markalı cihazları kullanılarak AgNP'lerin varlığı, indirgemeden sorumlu fitokimyasallara ait fonksiyonel gruplar incelendi.Rigaku Miniflex 600 model X-ışını Diftraktometresi (XRD) ile AgNP'lerin kristal yap1 ve boyutları değerlendirildi. AgNP'lerin morfolojik görünümlerinin belirlenmesinde EVO 40 LEQ Taramalı Elektron Mikroskobu (SEM) kullanıldı. RadB-DMAX II bilgisayar kontrollü Enerji Dağılımlı X-1şınımı Kırınımı (EDX) dataları ile elde edilen partiküllere ait element kompozisyonları, Malvern marka Zeta potansiyeli cihaz verileri ile de yüzey yük dağılımları belirlendi.

\section{Mikrodilusyon ile antimikrobiyal aktivitenin incelenmesi}

Biyosentez ile elde edilen AgNP'lerin antimikrobiyal aktiviteleri gram pozitif, negatif bakteriler ve maya patojen suşları üzerinde Mikrodilusyon ile Minimum İnhibisyon Konsantrasyonu (MİK) tespit edildi.

Gram pozitif Staphylococcus aureus (S. aureus) ATCC 29213, Bacillus subtilis (B. subtilis) ATCC 11774 suşları, gram negatif, Escherichia coli ( $E$. coli) ATCC25922, Pseudomonas aeruginosa ( $P$. aeruginosa) ATCC 27833 suşları ve maya

\section{Materyal ve metot}


Candida albicans (C. albicans) üzerinde AgNP'lerin antimikrobiyal aktiviteleri incelendi.

Her patojen suş için Mcfarland 0.5 [22] bulanıklı standard ile mikroorganizma çözeltileri hazırlandı. 96'lık plakalara gram pozitif ve negatif bakteriler için Muller Hinton siv1 besiyeri eklendi. $C$. albicans mikroorganizması için RPMI 1640 sıvı besiyeri kullanıldı. Her mikroorganzima için mikrodilusyonun başlıyacağı birinci kuyucuğa $20 \mu \mathrm{g} / \mathrm{mL}^{-1}$ olarak hazırlanan AgNP'lere ait çözeltisi eklendi. Birinci kuyucuktan başlıyıp kuyucuklara mikro dilusyon uyguland. üzerlerine Mc Farland 0.5 stanadart bulanıklığa göre hazırlanan mikroorganizma karışımlarından eklendi. AgNP'lerin etkilerini karşılaştırmak için gram pozitifler için vankomisin, gram negatifler için kolistin ve maya için flukanozol antibiyotikleri için de aynı uygulama adımları yürütüldü. Sentez için kullanılan $\mathrm{AgNO}_{3}$ çözeltisi içinde mikrodilusyon yapıldı. Uygulama yapılan mikro plakalar $37^{\circ} \mathrm{C}$ etüvde 24 saat süre ile inkübasyona alındı. Süre sonunda üreme kontrolu yapıldı. MIK için üremenin başladığ 1 kuyucuğun bir öncesine ait konsantrasyon belirlendi.

\section{Bulgular ve tartışma}

\section{AgNP'lerin karakterizasyonu}

Çörek otu özütü ile $\mathrm{AgNO}_{3}$ çözeltisinin bir araya gelmesinin ardından renk değişimi gözlendi. 30 dakika sonra meydana gelen sarıdan koyu kahve renk değişimi ile alınan numunelerin UV-vis. Spekrofotometrede 200-800 nm [23] dalga boyu taramaları yapıldı. Yapılan okumalarda 426.50 $\mathrm{nm}$ dalga boyuna sahip maksimum absorbanslar bulundu (şekil 1). Sulu ortamdaki $\mathrm{Ag}^{+}$iyonunun bioredüksiyonu ile plazma yüzeyinde meydana gelen titreşimlerin (SPR) meydana gelmesiyle sarıdan kahverengi renk değişimi AgNP'lerin oluşumunu göstermektedir [24]. UV-vis. spekrofotometrede ki renk değişimi ile yapılan okumalarda $426.50 \mathrm{~nm}$ dalga boyunda maksimum absorbans değerleride AgNP'lerin varlığını gösteren karakteristik bulgudur [23], [25].

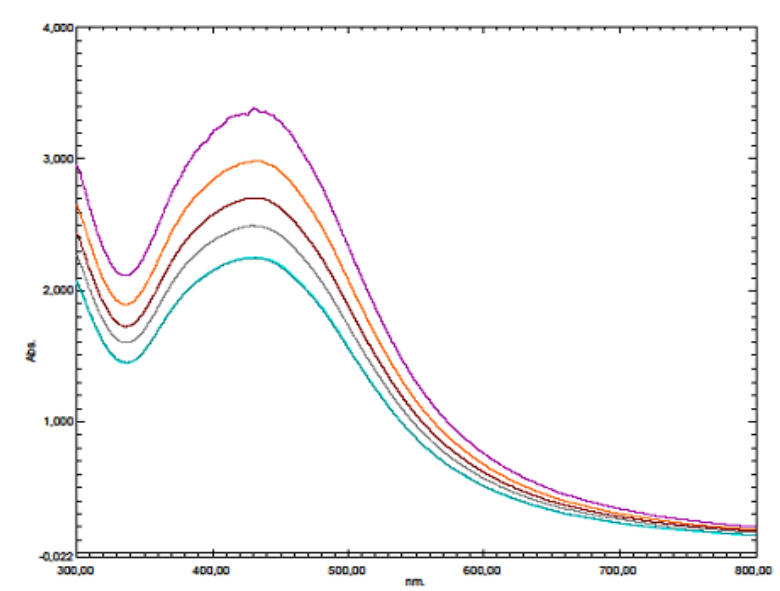

Şekil 1. UV-vis. Spektrofotometre spektrumlarl ile AgNP'lerin varlı̆

AgNP'lerin biyosentezinde indrigemeden sorumlu gruplarin 3332.71-3329.70 cm $\mathrm{cm}^{-1}$, $2125.73-2124.05 \mathrm{~cm}^{-1}$ ve $1636.02-1635.63 \mathrm{~cm}^{-1}$ spektrumlarında oluşan frekans kaymaları ile hidroksil grupların [17], metilen grupların [26] ve amino grupların [15] indirgemeden sorumlu olabileceğini göstermektedir (şekil 3).

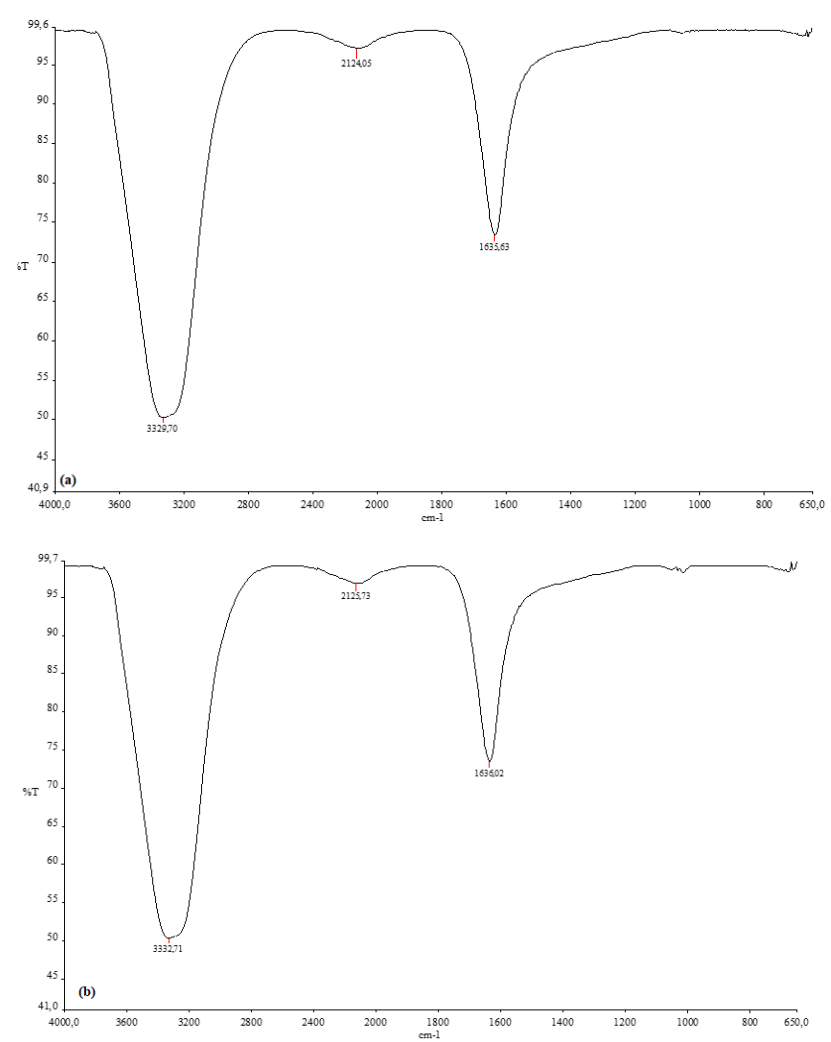

Şekil 2. FT-IR spektrumları (a) AgNP'lerin biyozentezi sonrası, (b) Nigella sativa L. özütü 
XRD ile $2 \theta$ da okunan datalarda (111), (200), (220) ve (311) de bulunan pikler AgNP'lerin kristal yapısına uyumludur [27]. Pikler gümüş nano kristallerin kubik yapida olduklarını göstermektedir [28]. Datalarda bu piklerin 38.11, $44.15,64.52$ ve 77.04 değerleri okundu. $2 \theta$ da ki değerler kullanılarak kristal nano boyut değerlendirildi (şekil 4). Debye-Scherrer formülü kullanılarak kristal nano boyut hesapland1 [29],[30].

$\mathrm{D}=\mathrm{K} \lambda /(\beta \cos \theta)$

Formül (1) de ;

$\mathrm{D}=$ partikül boyutu,

$\mathrm{K}=$ sabit değeri (0.90),

$\lambda=\mathrm{X}$-ray dalga boyu değeri (1.5418 $\AA$ ),

$\beta=$ En yüksek pikin FWHM değerinin yarısı,

$\theta=$ yüksek pikin Bragg açısını ifade eder.

Bu hesaplamaya göre AgNP'ler $17.68 \mathrm{~nm}$ kristal nano boyutta oldukları hesaplandı. Bu eşitlik kullanılarak AgNP'lerin kristal boyutunun hesaplandığı bazı çalışmalarda $21 \mathrm{~nm}$ [15] ve $18.17 \mathrm{~nm}$ [31] oldukları hesaplanmıştır.

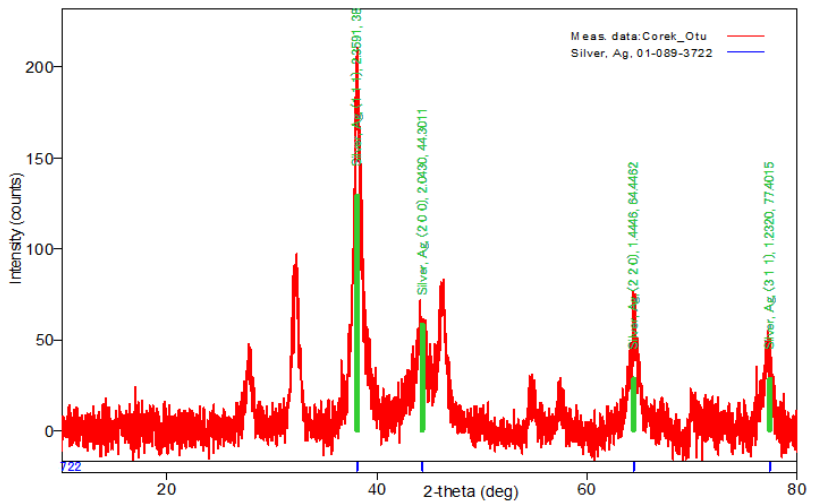

Şekil 4. AgNP'lerin krsistal desenine ait XRD datalarl

Elde edilen AgNP'lerin SEM görüntülerinde küresel morfolojik yap1 gösterdikleri belirlendi [32], [33]. EDX datalarında element kompozisyonları gümüşe ait güçlü piklerin oluşu ile AgNP'lerin varlığını destekleyici nitelik taşımaktadır [34]. EDX verilerinde Carbon ve oksijenden gibi elementlerden gelen zayıf pikler ise özütten gelen fitokimysallardan kaynaklanıyor olabilir [35].
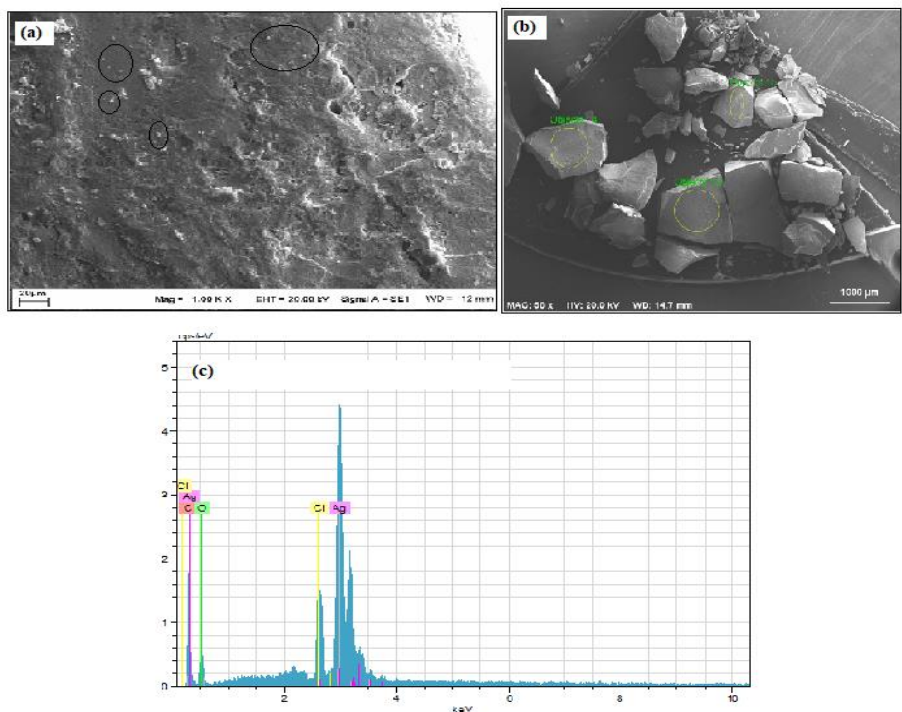

Şekil 5. AgNP'lerin (a)Morfolojik görümleri (b-

c) Element kompozisyonlarını içeren SEM mikrografisi ve EDX profili

AgNP'lerin yüzey yüklerine ait dağılımlarını belirlemek üzere yapılan Zeta potansiyeli analizi sonucu - $20.9 \mathrm{mV}$ olarak bulundu (Şekil 6).

AgNP'lerin bitkisel kaynaklı biyosentez çalışmalarında zeta potansiyel dağılımları -19.7 $\mathrm{mV}$ [27] ve $-19 \mathrm{mV}$ [36] olarak tespit edilmişitir.

Zeta potansiyelinin yani AgNP'lerin yüzey yüklerinin negatif karakter sergilemesi kümelenmenin olmadığını ve kararlı bir yapı sergilediklerini göstermektedir. Bu negatif yük AgNP'lerin yüzeyini kaplayan fitokimyasallardan kaynaklanıyor olabilir [37].

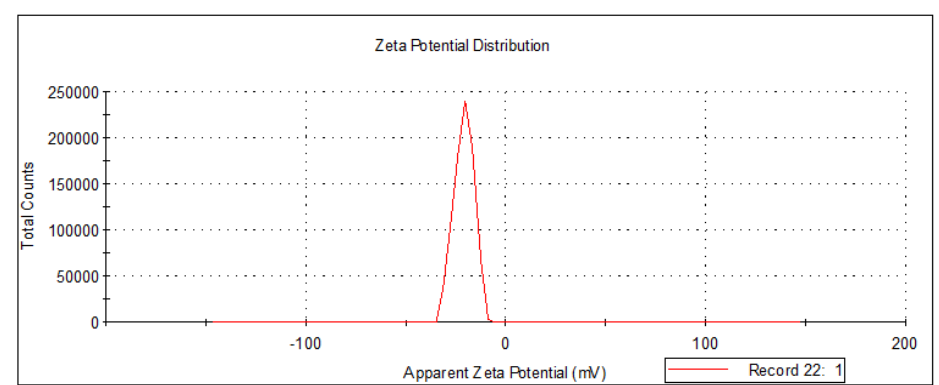

Şekil 6. AgNP'lerin yüzey yük dağılımı

\section{AgNP'lerin anti-mikrobiyal etkilerinin incelenmesi}

Tablo 1 ve şekil 2 de mikrodilusyon yöntemi ile patojen suşlar üzerinde AgNP'ler ve diğer karşılaştırma yapılan materyallerin 
antimikrobiyal aktiviteleri değerlendirildi. AgNP'lerin en düşük $0.03 \mu \mathrm{g} / \mathrm{mL}$ ile $S$. aureus üzerinde gümüş nitrat ve antibiyotikten düşük konsantrasyonda etkili oldukları görüldü. En yüksek $0.50 \mu \mathrm{g} / \mathrm{mL}$ ile $P$. aeruginosa üzerinde yine gümüss nitrat ve antibiyotiğe oranla daha düşük konsantrasyonla etkili olmuştur (şekil 3 ve tablo 1)

Tablo 1. AgNP'lerin, antibiyotiklerin ve gümüş nitrat çözeltisinin antimikrobiyal aktivitelerine ait MIK değerleri

\begin{tabular}{lccc}
\hline Patojen Sus & $\begin{array}{c}\text { AgNPs } \\
\boldsymbol{\mu g} / \mathbf{m L}\end{array}$ & $\begin{array}{c}\text { Gümüs } \\
\text { Nitrat } \\
\boldsymbol{\mu g} / \mathbf{m L}\end{array}$ & $\begin{array}{c}\text { Antibiyotik } \\
\boldsymbol{\mu g} / \mathbf{m L}\end{array}$ \\
\hline S. aureus ATCC 29213 & 0.03 & 2.65 & 2.00 \\
B.subtilis ATCC 11773 & 0.06 & 1.32 & 1.00 \\
$\begin{array}{l}\text { E. coli ATCC 25922 } \\
\text { P. aeruginosa }\end{array}$ & 0.12 & 0.66 & 2.00 \\
$\begin{array}{l}\text { ATCC27833 } \\
\text { C. albicans }\end{array}$ & 0.50 & 1.32 & 4.00 \\
\hline
\end{tabular}

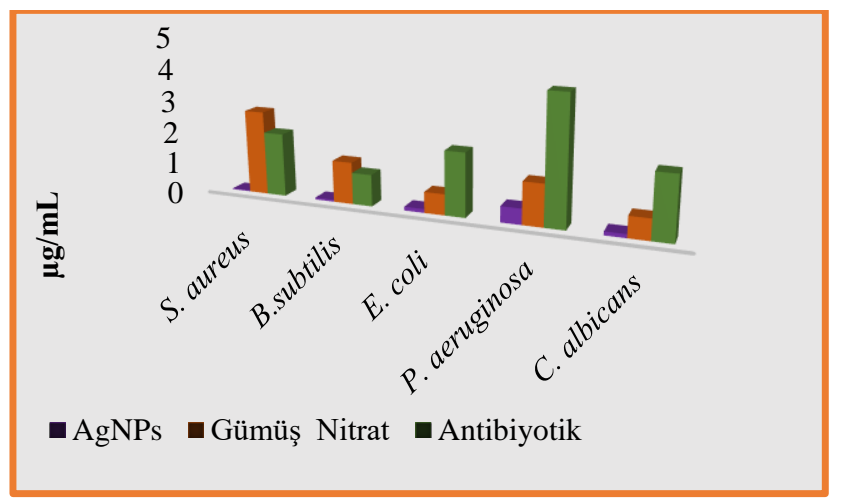

Şekil 7. AgNP'lerin, antibiyotik ve gümüş nitratın patojen suşlar üzerinde MiK değerleri

Gümüş iyonları sıvı bir yapıda iyonize olup yüksek reaktif özellik gösterir. Sıvı bir ortamda iyonize olan gümüş elektro statik çekim kuvvetiyle mikroorganizmalar ile etkileşime geçerler [38],[39]. Etkileşim sonucunda Reaktif oksijen türlerini (ROS) artırılar. Artan ROS miktarı hücrede membran gibi yapılara zarar verir [40]. Bununla birlikte hücrede önemli faaliyetlerin DNA, RNA ve bazı önemli enzimlerin işlevlerini bozarlar [42].

Benzer çalışmalarda biyosentez ile elde edilen AgNP'lerin patojen suşlara olan antimikrobiyal etkileri için yapılan bir çalışmada $B$. subtilis, $S$. aureus, E. coli ,P. aeruginosa ve $C$. albicans mikroorganizmaları için sırası ile 50, 50, 25, 50 ve $25 \mu \mathrm{g} / \mathrm{mL}$ konsantrasyonların etkili olduğu raporlanmıştır [30]. Başka bir çalışmada ise $S$. aureus, E. coli için 0.82 ve $0.67 \mu \mathrm{g} / \mathrm{mL}$ konsantrasyonların antimikrobiyal aktivitede etkili MIKK olduğu belirtilmiştir [41].

\section{Sonuçlar}

AgNP'lerin biyosentezinde Nigella sativa $L$. bitkisinden elde edilen özüt kullanılarak AgNP'ler basit, çevre dostu, düşük maliyetle sentezlendi. Sentez sonrası partiküller UV-vis. spektrofotometre, SEM, FTIR, EDX, XRD, ve Zeta potansiyeli analizlerinden yararlanarak karakterizasyonu yapıldı. Verilere göre AgNP'lerin küresel morfoloji sergiledikleri, $426.50 \mathrm{~nm}$ dalga boyunda maksimum absorbans sahip oldukları, kristal yapılarının kübik olduğu $23.66 \mathrm{~nm}$ kristal nano boyut ve son olarak da $20.9 \mathrm{mV}$ zeta potansiyeline sahip oldukları tespit edildi. AgNP'lerin patojen suşlar üzerinde antimikrobiyal aktivitelerinde antibiyotiklerden daha düşük konsantrasyonda etkili oldukları belirlendi.

AgNP'lerin oluşumuna etki eden faktörler üzerinde farklı uygulamalar yapılarak birçok alanda kullanımları sağlanabilir.

\section{Kaynaklar}

1. Solanki, J.N. and Murthy, Z.V.P., (2011). Controlled size silver nanoparticles synthesis with water-in-oil microemulsion method: A topical review. Industrial and Engineering Chemistry Research, 50, 12311-23.

2. Kumar, R., Ghoshal, G., Jain, A. and Goyal, M., (2017). Rapid Green Synthesis of Silver Nanoparticles (AgNPs) Using (Prunus persica) Plants extract: Exploring its Antimicrobial and Catalytic Activities. Journal of Nanomedicine \& Nanotechnology, 8, 1-8.

3. Eren, A., Baran, M.F., (2019) . Fist1k ( Pistacia vera L . ) Yaprağından Gümüş Nanopartikül ( AgNP )' lerin Sentezi , Karakterizasyonu ve Antimikrobiyal 
Aktivitesinin İncelenmesi Synthesis , Characterization and Investigation of Antimicrobial Activity of Silver Nanoparticles ( AgNP ). Türkiye Tarımsal Araştırmalar Dergisi 6, 165-73.

4. Baran, M.F., (2018). Green Synthesis of Silver Nanopartıcles (AGNPs) Using Pistacia Terebinthus Leaf Extract: Antımicrobial Effect And Characterization. International Journal on Mathematic, Engineering and Natural Sciences, 5, 67-75.

5. Baran, M., (2019). Prunus avium kiraz yaprağı özütü ile gümüş nanopartikül ( AgNP ) sentezi ve antimikrobiyal etkisinin incelenmesi. Dicle Üniversitesi Mühendislik Dergisi, 10, 221-7.

6. Baran, MF., Keskin, C., Atalar, MN., Baran, A., (2021). Environmentally Friendly Rapid Synthesis of Gold Nanoparticles from Artemisia absinthium Plant Extract and Application of Antimicrobial Activities. I $\check{g} d \imath r$ Üniversitesi Fen Bilimleri Enstitüsü Dergisi, 11, 365-75.

7. El-Batal, A.I., Al-Hazmi, N.E., Mosallam, F.M. and El-Sayyad, G.S., (2018). Biogenic synthesis of copper nanoparticles by natural polysaccharides and Pleurotus ostreatus fermented fenugreek using gamma rays with antioxidant and antimicrobial potential towards some wound pathogens. Microbial Pathogenesis, Elsevier Ltd. 118, 159-69.

8. Doğaroğlu, Z.G., Eren, A. and Baran, M.F., (2019). Effects of $\mathrm{ZnO}$ Nanoparticles and Ethylenediamine- N, N ' - Disuccinic Acid on Seed Germination of Four Different Plants. 1800111, 1-5.

9. Eren, A., Baran, M.F., (2019). Green Synthesis , Characterization And Antımicrobial Activity Of Silver Nanoparticles ( Agnps ) From Ma1ze ( Zea mays L .). Applied Ecology and Environmental Research, 17, 4097-105.

10. Baran, M.F., Saydut, A., Umaz, A.,
(2019). Gümüş nanomalzeme sentezi ve antimikrobiyal uygulamaları. Dicle Üniversitesi Mühendislik Dergisi, 10, 689-95.

11. Li, G., He, D., Qian, Y., Guan, B., Gao, S. and Cui, Y., (2012). Fungus-Mediated Green Synthesis of Silver Nanoparticles Using Aspergillus terreus. International Journal of Molecular Sciences, 13, 46676.

12. Mousavi, S.A., Almasi, A., Navazeshkh, F. and Falahi, F., (2019). Biosorption of lead from aqueous solutions by algae biomass: Optimization and modeling. Desalination and Water Treatment, 148, 229-37.

13. Gopalu, K., Matheswaran J., Alexander, G., Juan, Antonio LT., Evgeny, K., D.K., (2016). Rapid Biosynthesis of AgNPs Using Soil Bacterium Azotobacter vinelandii With Promising Antioxidant and Antibacterial Activities for Biomedical Applications. The Journal of The Minerals, Metals \& Materials Society, 69, 1206-12.

14. Baran, M.F., Koç, A. and Uzan, S., (2018). Kenger (Gundelia tournefortii) Yaprağı İle Gümüş Nanopartikül(Agnp) Sentezi, Karakterizasyonu ve Antimikrobiyal Uygulamalar1. International Journal on Mathematic, Engineering and Natural Sciences, 5, 44-52.

15. Khan, A.U., Yuan, Q., Khan, Z.U.H., Ahmad, A., Khan, F.U., Tahir, K, Ullah, S., (2018). An eco-benign synthesis of AgNPs using aqueous extract of Longan fruit peel: Antiproliferative response against human breast cancer cell line MCF-7, antioxidant and photocatalytic deprivation of methylene blue. Journal of Photochemistry and Photobiology B: Biology, 183, 367-73.

16. Velmurugan, P., Anbalagan, K., Manosathyadevan, M., Lee, K.J., Cho, M., Lee, S.M. Park, J. H., Oh, S. G., Bang, K. S., Oh, B. T., (2014). Green synthesis of silver and gold nanoparticles using Zingiber officinale root extract and 
antibacterial activity of silver nanoparticles against food pathogens. Bioprocess and Biosystems Engineering, 37, 1935-43.

17. Remya, R.R., Rajasree, S.R.R., Aranganathan, L. and Suman, T.Y., (2015). An investigation on cytotoxic effect of bioactive AgNPs synthesized using Cassia fistula flower extract on breast cancer cell MCF-7. Biotechnology Reports, Elsevier B.V. 8, 110-5.

18. Ali, M., Kim, B., Belfield, K.D., Norman, D., Brennan, M. and Ali, G.S., (2016). Green synthesis and characterization of silver nanoparticles using Artemisia absinthium aqueous extract - A comprehensive study. Materials Science and Engineering C, 58, 359-65.

19. Umaz, A., Koç, A., Baran, M.F. Keskin, C., Atalar, M.N., (2019). Hypericum Triquetrifolium Turra Bitkisinden Gümüş Nanopartiküllerin Sentezi, Karekterizasyonu ve Antimikrobial Etkinliğinin İncelenmesi. I $\breve{g} d ı r$ Üniversitesi Fen Bilimleri Enstitüsü Dergisi, 9, 1467-75.

20. Rajeshkumar, S. and Bharath, L. V., (2017). Mechanism of plant-mediated synthesis of silver nanoparticles - A review on biomolecules involved, characterisation and antibacterial activity. Chemico-Biological Interactions, Elsevier Ireland Ltd. 273, 219-27.

21. Gupta, S.D., Agarwal, A. and Pradhan, S., (2018). Phytostimulatory effect of silver nanoparticles (AgNPs) on rice seedling growth: An insight from antioxidative enzyme activities and gene expression patterns. Ecotoxicology and Environmental Safety, Elsevier Inc. 161, 624-33.

22. Baran, M.F., (2019). Synthesis and Antimicrobial Applications of Silver Nanoparticles From artemisia absinthium plant. Biological and Chemical Research, 6, 96-103.

23. Hafez, R.A., Abdel-wahhab, M.A., Sehab,
A.F. and El-din, A.A.K., (2017). Green synthesis of silver nanoparticles using Morus nigra leave extract and evaluation their antifungal potency on phytopathogenic fungi. Journal of Applied Pharmaceutical Science, 7, 41-8.

24. Kumar, V., Gundampati, R.K., Singh, D.K., Bano, D., Jagannadham, M. V. and Hasan, S.H., (2016). Photoinduced green synthesis of silver nanoparticles with highly effective antibacterial and hydrogen peroxide sensing properties. Journal of Photochemistry and Photobiology B: Biology, Elsevier B.V. 162, 374-85.

25. Pechyen, C., (2020). A flower shape-green synthesis and characterization of silver nanoparticles ( AgNPs ). Integrative Medicine Research, Korea Institute of Oriental Medicine. 9, 11003-12.

26. Baran., M.F., (2019). Synthesis , Characterization and Investigation of Antimicrobial Activity of Silver Nanoparticles From Cydonia Oblonga Leaf. Applied Ecology and Environmental Research, 17, 2583-92.

27. Dubey, S.P., Dwivedi, A.D., Lahtinen, M., Lee, C., Kwon, Y.N. and Sillanpaa, M., (2013). Protocol for development of various plants leaves extract in single-pot synthesis of metal nanoparticles. Spectrochimica Acta - Part A: Molecular and Biomolecular Spectroscopy, Elsevier B.V. 103, 134-42.

28. Sampaio, S. and Viana, J.C., (2018). Production of silver nanoparticles by green synthesis using artichoke (Cynara scolymus L.) aqueous extract and measurement of their electrical conductivity. Advances in Natural Sciences: Nanoscience and Nanotechnology, IOP Publishing. 9, 1-10.

29. Rolim, W.R., Pelegrino, M.T., de Araújo Lima, B., Ferraz, L.S., Costa, F.N., Bernardes, J.S. Rodigues, T. B., Marcelo S., Amedea B., (2019). Green tea extract mediated biogenic synthesis of silver nanoparticles:

Characterization, 
cytotoxicity evaluation and antibacterial activity. Applied Surface Science, Elsevier. 463, 66-74.

30. Baran, M. F., Saydut, A., (2019). Altın nanomalzeme sentezi ve karekterizasyonu. Dicle Üniversitesi Mühendislik Dergisi, 10, 1033-40.

31. Baran, M.F., Koç, A., ve Uzan, S., (2018). Kenger (Gundelia tournefortii) Yaprağ 1 İle Gümüş Nanopartikül(Agnp) Sentezi, Karakterizasyonu ve Antimikrobiyal Uygulamalar1. International Journal on Mathematic, Engineering and Natural Sciences, 5, 44-52

32. Kumar, B., Smita, K., Cumbal, L. and Debut, A., (2015). Green synthesis of silver nanoparticles using Andean blackberry fruit extract. Saudi Journal of Biological Sciences, King Saud University. 24, 45-50.

33. Ali, M.H., (2020). Eco-friendly synthesis of silver nanoparticles from crust of Cucurbita Maxima L. (red pumpkin). EurAsian Journal of BioSciences Eurasia J Biosci, 14, 2829-33.

34. Shaheen, T.I. and Abd El Aty, A.A., (2018). In-situ green myco-synthesis of silver nanoparticles onto cotton fabrics for broad spectrum antimicrobial activity. International Journal of Biological Macromolecules, Elsevier B.V. 118, 2121-30.

35. Arumai Selvan, D., Mahendiran, D., Senthil Kumar, R. and Kalilur Rahiman, A., (2018). Garlic, green tea and turmeric extracts-mediated green synthesis of silver nanoparticles: Phytochemical, antioxidant and in vitro cytotoxicity studies. Journal of Photochemistry and Photobiology B: Biology, 180, 243-52.

36. Oliveira, A.C. de J., Araújo, A.R. de, Quelemes, P.V., Nadvorny, D., SoaresSobrinho, J.L., Leite, J.R.S. de A. da Silva-Filho, E., Silva, D. A., (2019). Solvent-free production of phthalated cashew gum for green synthesis of antimicrobial silver nanoparticles.
Carbohydrate Polymers, Elsevier. 213, 176-83.

37. Patil, M.P., Singh, R.D., Koli, P.B., Patil, K.T., Jagdale, B.S., Tipare, A.R., (2018). Antibacterial potential of silver nanoparticles synthesized using Madhuca longifolia flower extract as a green resource. Microbial Pathogenesis, Elsevier Ltd. 121, 184-9.

38. Swamy, M.K., Akhtar, M.S., Mohanty, S.K. and Sinniah, U.R., (2015). Synthesis and characterization of silver nanoparticles using fruit extract of Momordica cymbalaria and assessment of their in vitro antimicrobial, antioxidant and cytotoxicity activities. Spectrochimica Acta - Part A: Molecular and Biomolecular Spectroscopy, 151, 939-44.

39. Durán, N., Durán, M., Jesus, M.B. De, Seabra, A.B., Fávaro, W.J. and Nakazato, G., (2015). Silver Nanoparticles: A New View on Mechanistic Aspects on Antimicrobial Activity. Nanomedicine: Nanotechnology, Biology, and Medicine, Elsevier B.V. 12, 789-99.

40. Singh, P., Garg, A., Pandit, S. and Mokkapati, V.R.S.S., (2018). Antimicrobial Effects of Biogenic Nanoparticles. Nanomaterials, 8, 1-19.

41. Gopinath, V., Priyadarshini, S., Loke, M.F., Arunkumar, J., Marsili, E., MubarakAli, D. et al., (2017). Biogenic synthesis, characterization of antibacterial silver nanoparticles and its cell cytotoxicity. Arabian Journal of Chemistry, King Saud University. 10, 1107-17. 